\title{
Sinterability of nanopowders of terbia solid solutions with scandia, yttria, and lutetia
}

\author{
Stanislav S. BALABANOV ${ }^{a, *}$, Dmitry A. PERMIN ${ }^{a}$, Elena Ye. ROSTOKINA ${ }^{a}$, \\ Sergey V. EGOROV ${ }^{b}$, Andrey A. SOROKIN ${ }^{b}$ \\ ${ }^{a}$ G.G. Devyatykh Institute of Chemistry of High-Purity Substances RAS, Nizhny Novgorod, Russia \\ ${ }^{b}$ Federal Research Center, the Institute of Applied Physics RAS, Nizhny Novgorod, Russia
}

Received: Feburary 8, 2018; Revised: June 7, 2018; Accepted: June 19, 2018

(C) The Author(s) 2018. This article is published with open access at Springerlink.com

\begin{abstract}
The synthesis of nanopowders of terbia compounds with scandia, yttria, and lutetia was carried out using a self-propagating high-temperature synthesis method involving a mixture of nitrates of metals and glycine as a precursor. The nanopowder phase transformations were investigated using $\mathrm{X}$-ray diffraction analysis. It was found that lutetia has a negligible effect on the phase formation in terbia. On the other hand, yttrium and scandium ions significantly suppressed crystallization. The densification kinetics of nanopowders of the $\mathrm{Tb}_{2} \mathrm{O}_{3}$ compounds and the microstructure of ceramics after microwave sintering were studied using dilatometry and scanning electron microscopy. The introduction of scandia, yttria, or lutetia contributed to the intensification of the densification of the terbia ceramics when heated in a microwave field. Near full-density materials of terbia solid solutions with lutetia and yttria were obtained at about $1600-1640{ }^{\circ} \mathrm{C}$. The ceramics of scandia-terbia compounds contained the second phase, which causes light scattering.
\end{abstract}

Keywords: terbia; microwave sintering; X-ray analysis; ceramics

\section{Introduction}

The fabrication of new crystalline materials for extreme light fields is one of the priorities of the science of advanced laser materials. One of the most urgent tasks in this field is the search for new Faraday isolator (FI) media. Such media should possess a high magnetic figure of merit and high thermal conductivity, low absorption and scattering coefficients at working wavelengths, and be potentially available for manufacturing with apertures of tens and hundreds of millimeters (to reduce the power density of radiation and any nonlinear effects

* Corresponding author.

E-mail: Balabanov@ihps.nnov.ru that might arise). The most common magneto-optical material used in modern FI in the wavelength range of $400-1100 \mathrm{~nm}$ is terbium-gallium garnet $\mathrm{Tb}_{3} \mathrm{Ga}_{5} \mathrm{O}_{12}$ (TGG) single crystal. This is due to its relatively high values of the Verdet constant, high thermal conductivity, and low absorption coefficient $\left(<0.1 \mathrm{~cm}^{-1}\right.$ at $\left.1064 \mathrm{~nm}\right)$ [1]. However, the possibility of increasing the efficiency of magneto-optical media based on TGG single crystal is limited by the dimensions of the grown single crystal. Ceramic approaches developed over the past two decades in terms of obtaining highly transparent laser materials, have revealed the possibilities of creating new media with dimensions sufficient for use in highpower laser sources. A transparent TGG ceramic was first fabricated by Dr. Ikesue in 2002, and the possibility 
of its use in a high-power FI was reported in 2003 [2]. Further experiments confirmed the possibility of replacing the single crystal material with ceramics without a loss of functionality. In recent years some works have been published on the production of magneto-optical ceramics based on terbium-aluminum garnet $\mathrm{Tb}_{3} \mathrm{Al}_{5} \mathrm{O}_{12}$ (TAG) [3,4] and terbium scandium aluminum garnet crystals (TSAG) [5,6], possessing a higher Verdet constant value and better thermo-optical properties in comparison with TGG. However, the use of these materials is limited by the maximum possible concentration of terbium in the structural unit (37.5 at\%), which determines the Verdet constant.

In Ref. [7], it is reported that $\mathrm{Tb}_{2} \mathrm{O}_{3}$ ceramics with a Verdet constant more than three times higher than that for the TGG material within the 380-1750 nm transparency range, can be produced. Nevertheless, the ceramic samples used were not of laser quality. $\mathrm{Tb}_{2} \mathrm{O}_{3}$ ceramics technology is complicated by a number of issues. One of them is the mixed-valence state of terbium ions. There are several binary terbium oxides containing both $\mathrm{Tb}^{3+}$ and $\mathrm{Tb}^{4+}$ ions of various compositions $\mathrm{TbO}_{x}(1.5<x \leqslant 2)$. At that $\mathrm{Tb}_{2} \mathrm{O}_{3}$ is easily oxidated at intermediate temperatures [8]. In the case of $\mathrm{TbO}_{x}$ powders sintering to $\mathrm{Tb}_{2} \mathrm{O}_{3}$ ceramics, oxygen gas is released inside the material during the sintering process $\left(\mathrm{TbO}_{x} \leftrightarrow \mathrm{TbO}_{1.5}+y \mathrm{O}_{2}\right)$ and the ceramics finally crack and/or break into pieces. Moreover, terbium(III) oxide undergoes a series of polymorphic transformations at high temperatures (near 1600, 2160, and $2340{ }^{\circ} \mathrm{C}$ ), which causes volumetric change in the material, and induces mechanical stress and cracking [9-11]. Apparently, the maximum sintering temperature of $\mathrm{Tb}_{2} \mathrm{O}_{3}$ ceramics is limited to about $1500-1550{ }^{\circ} \mathrm{C}$ without sintering aid. Therefore, one of the most important tasks of the $\mathrm{Tb}_{2} \mathrm{O}_{3}$ ceramics technology is the search for sintering aid, in that this can promote sintering at lower temperatures, and/or can prevent the phase transitions at sintering temperatures and/or suppress mechanical stress caused by these phase transitions.

Such aids (or components, due to their high concentration in ceramics) may be rare earth sesquioxides (REO) such as $\mathrm{Y}_{2} \mathrm{O}_{3}, \mathrm{Sc}_{2} \mathrm{O}_{3}$, or $\mathrm{Lu}_{2} \mathrm{O}_{3}$. However, information on obtaining $\mathrm{Tb}_{2} \mathrm{O}_{3}$ optical ceramic materials with REO is very limited [12]. In Refs. $[13,14]$, the production of terbia solid solutions with oxides of some rare earth elements was reported. In addition, their existence ranges are determined, and the questions of phase relationships (phase formation) in the systems $\mathrm{YO}_{1.5}-\mathrm{TbO}_{1.5}, \quad \mathrm{Lu}_{2} \mathrm{O}_{3}-\mathrm{Tb}_{2} \mathrm{O}_{3}-\mathrm{TiO}_{2}$ are considered.

In the present study, we report on the obtained nanopowders of $\mathrm{ScO}_{1.5}-\mathrm{TbO}_{1.5}, \mathrm{YO}_{1.5}-\mathrm{TbO}_{1.5}$, and $\mathrm{LuO}_{1.5}-\mathrm{TbO}_{1.5}$ compounds and $\mathrm{Tb}_{2} \mathrm{O}_{3}$ by self-propagating high-temperature synthesis using a mixture of nitrates of metals and glycine as a precursor. In addition, we study of the effect of scandia, yttria, and lutetia concentrations on the phase composition and the densification kinetics of the obtained powders, as well as the possibility of producing ceramics from these powders.

\section{Experimental}

Terbium(III, IV) oxide powders $\left(\mathrm{Tb}_{4} \mathrm{O}_{7}, 99.99 \%\right.$ purity), yttrium oxide powders $\left(\mathrm{Y}_{2} \mathrm{O}_{3}, 99.99 \%\right)$, scandium oxide powders $\left(\mathrm{Sc}_{2} \mathrm{O}_{3}, 99.99 \%\right)$, lutetium oxide powders $\left(\mathrm{Lu}_{2} \mathrm{O}_{3}, 99.99 \%\right)$, nitric acid (99.999\%), hydrogen peroxide (30\% high-purity grade solution), and glycine (aminoacetic acid, $\mathrm{NH}_{2} \mathrm{CH}_{2} \mathrm{COOH}, 99.9 \%$ ) were used as the starting materials in the present work.

The synthesis of powders of terbia compounds with scandia, yttria, and lutetia was carried out using the selfpropagating high-temperature synthesis (SHS) method involving a mixture of nitrates of metals and glycine as a precursor. Terbium nitrate $\mathrm{Tb}\left(\mathrm{NO}_{3}\right)_{3}$ was prepared by dissolving $\mathrm{Tb}_{4} \mathrm{O}_{7}$ powders in a mixture of nitric acid $(2 \mathrm{~N})$ and hydrogen peroxide according to the procedure, described in Ref. [9]. $\mathrm{Y}\left(\mathrm{NO}_{3}\right)_{3}, \mathrm{Sc}\left(\mathrm{NO}_{3}\right)_{3}$, and $\mathrm{Lu}\left(\mathrm{NO}_{3}\right)_{3}$ were obtained by dissolving the corresponding metal oxide in nitric acid $(2 \mathrm{~N})$. Glycine was then added to the mixture of nitrates of the corresponding metals in a molar ratio of $1: 1$. The resulting glycine-nitrate solution was divided into portions, put in a quartz flask, and placed in a resistance furnace which had been preheated to $450{ }^{\circ} \mathrm{C}$. The heating of the precursor led to the initiation of redox reactions and the promotion of the SHS. The combustion process was accompanied by intense gas formation. At the end of the combustion process, solid foam consisting of nanodisperse oxide particles was formed. Powders of thirteen various compositions $\left(\mathrm{Y}_{1-x} \mathrm{~Tb}_{x}\right)_{2} \mathrm{O}_{3},\left(\mathrm{Sc}_{1-x} \mathrm{~Tb}_{x}\right)_{2} \mathrm{O}_{3},\left(\mathrm{Lu}_{1-x} \mathrm{~Tb}_{x}\right)_{2} \mathrm{O}_{3}$ $(x=0,0.3,0.6,0.9,1)$ were obtained. SHS terbiacontaining powders had brown colors of different intensities (the lightest shade is characteristic for $\left(\mathrm{Sc}_{1-x} \mathrm{~Tb}_{x}\right)_{2} \mathrm{O}_{3}$ compounds) due to the oxidation of 
terbium ions during combustion. Additionally, the reduction of SHS powders was carried out by their calcination under a vapor flow of isopropyl alcohol at $650{ }^{\circ} \mathrm{C}$.

The sintering of the ceramics based on terbia solid solutions or compounds with scandia, yttria, and lutetia was carried out by heating in a microwave (MW) field. The SHS powders were uniaxially pressed under 100 MPa into disks with a diameter of $10 \mathrm{~mm}$ and a thickness of $1 \mathrm{~mm}$. The sintering of the powder compacts was carried out using a gyrotron-based setup operating at a frequency of $24 \mathrm{GHz}$ with a regulated microwave power of up to $6 \mathrm{~kW}$. The samples were placed in a thermo-insulated unit made of radio-transparent and heat-resistant porous material based on $\mathrm{Al}_{2} \mathrm{O}_{3}$. Such a unit made it possible to reduce heat loss significantly and to enhance the uniformity of the temperature distribution in a sample during its microwave heating. The thermo-insulated sample was located in the middle part of the working chamber of the gyrotron setup (typical size of the chamber was $L \approx 50 \lambda_{\mathrm{em}}$, where $\lambda_{\mathrm{em}}=1.25 \mathrm{~cm}$ is the electromagnetic wavelength). The sample temperature was measured by an unshielded B-type thermocouple (Pt30\%Rh/Pt6\%Rh), which touched the bottom surface of the sample. The microwave sintering of the powder compacts was carried out at a residual air pressure of no more than $0.5 \mathrm{~Pa}$. The maximum sintering temperature varied from 1450 to $1650{ }^{\circ} \mathrm{C}$, and the sintering time ranged from 15 to $210 \mathrm{~min}$. After the completion of the calcination, the microwave power was switched off automatically, and the powders, located in the thermo-insulated unit, were initially cooled at a rate of about $90 \mathrm{~K} / \mathrm{min}$ then free-cooled at a lower rate.

$\mathrm{X}$-ray diffraction (XRD) analysis of the powders $\left(\mathrm{Y}_{1-x} \mathrm{~Tb}_{x}\right)_{2} \mathrm{O}_{3},\left(\mathrm{Sc}_{1-x} \mathrm{~Tb}_{x}\right)_{2} \mathrm{O}_{3},\left(\mathrm{Lu}_{1-x} \mathrm{~Tb}_{x}\right)_{2} \mathrm{O}_{3}(x=0,0.3$, $0.6,0.9,1)$ was done using an Ultima IV (Rigaku, Japan) $\mathrm{X}$-ray diffractometer $(\mathrm{Cu} \mathrm{K} \alpha$ radiation, $\lambda=$ $1.5406 \AA$ ). XRD was carried out in a range of angles
$2 \theta=15^{\circ}-60^{\circ}$ with a step of $0.02^{\circ}$, and an accumulation time of $1 \mathrm{~s}$. The study of the phase composition was performed just after obtaining the SHS powders and their reduction (in a resistance furnace under a vapor flow of isopropyl alcohol at $650{ }^{\circ} \mathrm{C}$ ). The morphology of the powders, the ceramic microstructure, and the average grain size were studied using an analytical scanning electron microscope (SEM) JEOL-6390LA using the imaging of back-scattered and secondary electrons. The sample density was determined by hydrostatic weighing with an accuracy of $0.01 \mathrm{~g} / \mathrm{cm}^{3}$. The theoretical density of the solid solutions was calculated by the additive method.

The densification kinetics of solid solution or compound compacts $\left(\mathrm{Y}_{1-x} \mathrm{~Tb}_{x}\right)_{2} \mathrm{O}_{3}, \quad\left(\mathrm{Sc}_{1-x} \mathrm{~Tb}_{x}\right)_{2} \mathrm{O}_{3}, \quad\left(\mathrm{Lu}_{1-x} \mathrm{~Tb}_{x}\right)_{2} \mathrm{O}_{3}$ $(x=0,0.3,0.6,0.9,1)$ was investigated using a NETZSCH DIL 402C dilatometer (Netzsch) at a heating rate of $5 \mathrm{~K} / \mathrm{min}$ at temperatures of up to $1530{ }^{\circ} \mathrm{C}$, and under high vacuum conditions.

\section{Results and discussion}

The resulting powders $\left(\mathrm{Y}_{1-x} \mathrm{~Tb}_{x}\right)_{2} \mathrm{O}_{3},\left(\mathrm{Sc}_{1-x} \mathrm{~Tb}_{x}\right)_{2} \mathrm{O}_{3}$, $\left(\mathrm{Lu}_{1-x} \mathrm{~Tb}_{x}\right)_{2} \mathrm{O}_{3}(x=0.3,0.6,0.9,1)$ have a sponge-like structure typical of SHS with randomly distributed pores, formed as a result of the intense gas formation during the synthesis process, and consisting of primary particles of several tens of nanometers in size (Fig. 1).

Figure 2 shows the $\mathrm{X}$-ray diffraction patterns of the as-synthesized and reduced $\left(\mathrm{Y}_{1-x} \mathrm{~Tb}_{x}\right)_{2} \mathrm{O}_{3},\left(\mathrm{Sc}_{1-x} \mathrm{~Tb}_{x}\right)_{2} \mathrm{O}_{3}$, $\left(\mathrm{Lu}_{1-x} \mathrm{~Tb}_{x}\right)_{2} \mathrm{O}_{3}(x=0.3,0.6,0.9,1)$ nanopowders. For comparison, Fig. 2 consists of the X-ray diffraction patterns of pristine yttria, lutetia, and scandia SHS powders.

SHS powders of pristine terbia $(x=1)$ consist of a mixture of crystalline phases. The peaks' positions in accordance with the theoretical X-ray Bragg reflections are most characteristic for compositions of $\mathrm{Tb}_{7} \mathrm{O}_{12}$ and
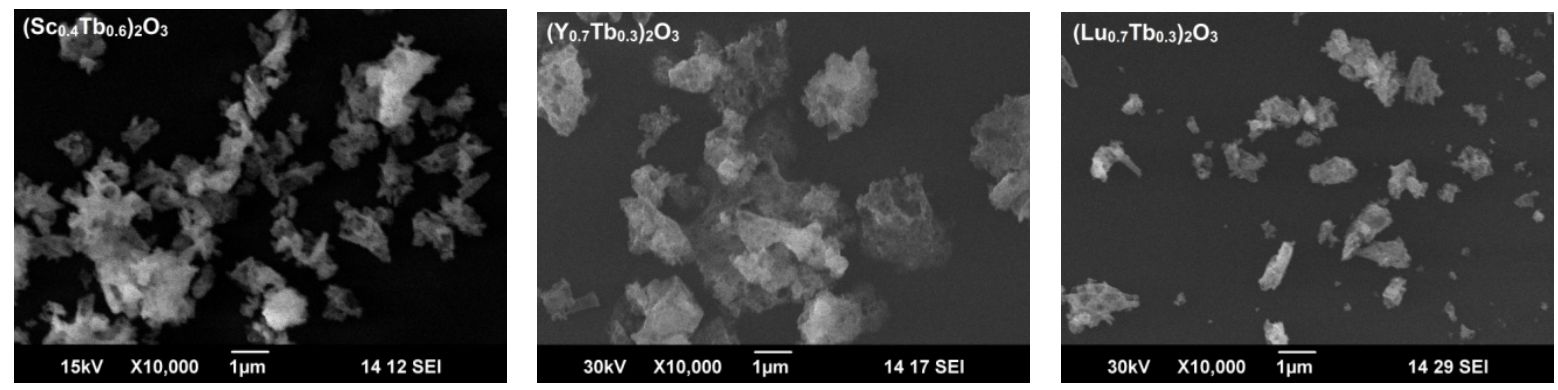

Fig. 1 SEM images of the powders of $\left(\mathrm{Sc}_{0.4} \mathrm{~Tb}_{0.6}\right)_{2} \mathrm{O}_{3},\left(\mathrm{Y}_{0.7} \mathrm{~Tb}_{0.3}\right)_{2} \mathrm{O}_{3}$, and $\left(\mathrm{Lu}_{0.7} \mathrm{~Tb}_{0.3}\right)_{2} \mathrm{O}_{3}$ after the SHS. 

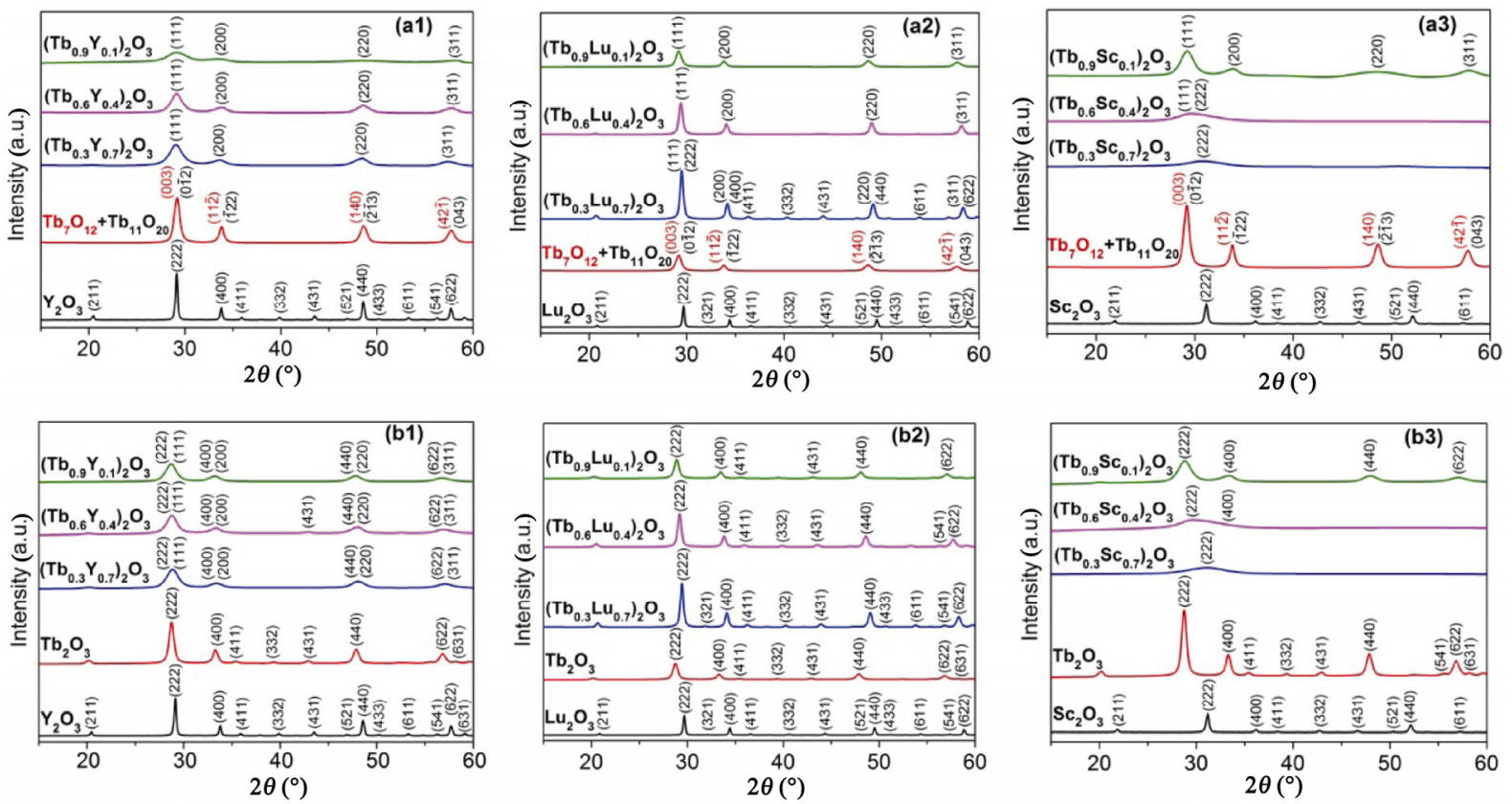

Fig. 2 XRD patterns of the powders (a1-a3) after the SHS and (b1-b3) after reducing in isopropyl alcohol vapor.

$\mathrm{Tb}_{11} \mathrm{O}_{20}$ intermediate phases [15]. The observed peaks are broadened due to low crystallite sizes and low crystallinity. Annealing of the SHS powders in a vapor flow of isopropyl alcohol at $650{ }^{\circ} \mathrm{C}$ leads to the reduction of terbium ions to the trivalent state. All diffraction peaks can be readily assigned to a pure cubic phase of $\mathrm{Tb}_{2} \mathrm{O}_{3}$ (the space group $I a \overline{3}$ ) according to ICDD No. 00-023-1418 with a unit cell dimension of $10.730 \AA$.

In $\left(\mathrm{Y}_{1-x} \mathrm{~Tb}_{x}\right)_{2} \mathrm{O}_{3}(x=0.3,0.6,0.9)$ terbia-yttria SHS powders (Fig. 2(a1)), there is a solid solution of cubic $\mathrm{Y}_{2} \mathrm{O}_{3}$ and triclinic $\mathrm{Tb}_{11} \mathrm{O}_{20}+$ trigonal $\mathrm{Tb}_{7} \mathrm{O}_{12}$ for all the compositions under consideration. The peaks' positions for all three samples are almost the same, which is explained by the great similarity of the yttria and terbia XRD patterns, and by the significant peak broadening.

An appreciable amount of cubic $\mathrm{Tb}_{2} \mathrm{O}_{3}(10.7290 \AA)$ appears in reduced powders of the same composition (Fig. 2(b1)). This manifests itself in a general shift of the peaks to the left and the appearance of a peak in the region of $\sim 20^{\circ}$, which is not typical for other phases. The presence of cubic $\mathrm{Tb}_{2} \mathrm{O}_{3}$ is less obvious in powders with an yttrium content of $70 \mathrm{~mol} \%\left(\mathrm{Y}_{0.7} \mathrm{~Tb}_{0.3}\right)_{2} \mathrm{O}_{3}$.

In the SHS powders of the terbia-lutetia $\left(\mathrm{Lu}_{1-x} \mathrm{~Tb}_{x}\right)_{2} \mathrm{O}_{3}$ system $(x=0.3,0.6,0.9)$ (Fig. 2(a2)), the peaks shift to the region of smaller diffraction angles (since the interplanar distance of $\mathrm{Tb}_{2} \mathrm{O}_{3}$ is greater) and the peaks' intensity decreases as the $\mathrm{Lu}_{2} \mathrm{O}_{3}$ content in the mixture diminishes. Samples with a lutetium content of 40 and $70 \mathrm{~mol} \%$ represent the solid solutions of cubic $\mathrm{Lu}_{2} \mathrm{O}_{3}$ and mixtures of triclinic $\mathrm{Tb}_{11} \mathrm{O}_{20}$ and trigonal $\mathrm{Tb}_{7} \mathrm{O}_{12}$ terbium oxides. The XRD patterns of the sample with a lutetium content of $10 \mathrm{~mol} \%$ is identical to that of $100 \%$ terbium oxide, i.e., a mixture of $\mathrm{Tb}_{11} \mathrm{O}_{20}+$ $\mathrm{Tb}_{7} \mathrm{O}_{12}$ phases.

In the reduced $\left(\mathrm{Lu}_{1-x} \mathrm{~Tb}_{x}\right)_{2} \mathrm{O}_{3}$ powders (Fig. 2(b2)), the existence of a solid solution of cubic lutetia and terbia with the same type of lattice symmetry is observed for all three dopant concentrations.

A different feature is observed in the terbia-scandia system $\left(\mathrm{Sc}_{1-x} \mathrm{~Tb}_{x}\right)_{2} \mathrm{O}_{3}(x=0.3,0.6,0.9)$ (Fig. 2(a3)). At a scandia content of 40 and $70 \mathrm{~mol} \%$, a broad peak is observed in the $30^{\circ}$ angle region, corresponding to the scandia maximum peak, which is substantially amorphized. At a scandia content of $40 \mathrm{~mol} \%$, the broad peak observed is somewhat shifted to the left, towards the terbium oxide peak position, which probably indicates a mixture of oxides. The XRD pattern of the sample with a scandia content of $10 \mathrm{~mol} \%$ is almost identical to that of the $100 \%$ terbium oxides $\mathrm{Tb}_{11} \mathrm{O}_{20}+$ $\mathrm{Tb}_{7} \mathrm{O}_{12}$.

The XRD patterns of reduced powders with a scandia content of 40 and $70 \mathrm{~mol} \%$ (Fig. 2(b3)) differ very little from those of unreduced powders of the same composition. At a scandia content of $10 \mathrm{~mol} \%$, the peak position is somewhat shifted to the left. A slight peak appears in the $20^{\circ}$ angle region, which may 
indicate the onset of a phase transformation of triclinic $\mathrm{Tb}_{11} \mathrm{O}_{20}$ and trigonal $\mathrm{Tb}_{7} \mathrm{O}_{12}$ into a cubic structure.

The sizes of coherent-scattering regions calculated using the Scherrer's equation are presented in Table 1. It can be seen that the sizes of the coherent-scattering regions are 3-10 times smaller in scandia- and yttriacontaining powders than in the lutetia-containing ones. Thus, yttrium and scandium ions substantially suppress the crystallization of the $\mathrm{Tb}_{2} \mathrm{O}_{3}$ powders, despite the fact that the $\mathrm{Y}^{3+}$ has an ionic radius closer to $\mathrm{Tb}^{3+}$ than the $\mathrm{Sc}^{3+}$ and $\mathrm{Lu}^{3+}$ ions.

Figure 3 shows the results of the dilatometric analysis of compounds of terbia with scandia, yttria, and lutetia $(x=0.3,0.6,0.9)$ powder compacts, and individual oxides $(x=0,1)$. The densification of the pristine terbia sample $(x=1)$ begins at $567{ }^{\circ} \mathrm{C}$, and the compact exhibits a total shrinkage of about $29 \%$ at $1520{ }^{\circ} \mathrm{C}$. An intensive change in the shrinkage rate of the sample begins at $699{ }^{\circ} \mathrm{C}$ and ends at $955{ }^{\circ} \mathrm{C}$. In this temperature range, the reduction of the $\mathrm{Tb}^{4+}$ ions takes place. These ions have significant solubility in cubic $\mathrm{Tb}_{2} \mathrm{O}_{3}$ (up to $10 \%$ [9]) and can remain due to the incomplete reduction of the powdes in alcohol vapor. Also, at these temperatures, an intense crystallization of powders occurs (SHS terbia powders, as well as scandia, yttria, and lutetia, have a low crystallinity after synthesis). This process can provide the system with an additional driving force leading to densification. It is known that a lattice transformation can activate the process of dislocation diffusion, resulting in the effective densification of ceramics [16]. After the reduction of $\mathrm{TbO}_{x}$, the linear shrinkage of the sample continues up to a temperature of $1370{ }^{\circ} \mathrm{C}$, after which the shrinkage rate begins to decrease.

A similar behavior is observed with regard to the $\mathrm{Tb}_{2} \mathrm{O}_{3}-\mathrm{Lu}_{2} \mathrm{O}_{3}$ system. The introduction of $10 \mathrm{~mol} \%$ of lutetia has a very limited effect on the densification rate of the samples compared with pristine terbia in the temperature range up to $1000-1100{ }^{\circ} \mathrm{C}$, but the shrinkage
Table 1 Sizes of coherent-scattering regions of $\left(\mathrm{Y}_{1-x} \mathrm{~Tb}_{x}\right)_{2} \mathrm{O}_{3},\left(\mathrm{Sc}_{1-x} \mathrm{~Tb}_{x}\right)_{2} \mathrm{O}_{3},\left(\mathrm{Lu}_{1-x} \mathrm{~Tb} \mathrm{~b}_{x}\right)_{2} \mathrm{O}_{3}$ powders

(Unit: $\AA$ )

\begin{tabular}{cccc}
\hline$x$ & $\left(\mathrm{Sc}_{1-x} \mathrm{~Tb}_{x}\right)_{2} \mathrm{O}_{3}$ & $\left(\mathrm{Y}_{1-x} \mathrm{~Tb}_{x}\right)_{2} \mathrm{O}_{3}$ & $\left(\mathrm{Lu}_{1-x} \mathrm{~Tb}_{x}\right)_{2} \mathrm{O}_{3}$ \\
\hline 0.3 & $20.8(4)$ & $53.9(5)$ & $231.8(15)$ \\
0.6 & $19.7(4)$ & $62.5(6)$ & $194.6(9)$ \\
0.9 & $52.9(15)$ & $38.7(7)$ & $152.3(12)$ \\
\hline
\end{tabular}

rate increases with increasing temperature, which is characterized by a wide halo at temperatures above $1000{ }^{\circ} \mathrm{C}$. The $\left(\mathrm{Lu}_{0.1} \mathrm{~Tb}_{0.9}\right)_{2} \mathrm{O}_{3}$ compact exhibits a total shrinkage of about $33 \%$ at $1520{ }^{\circ} \mathrm{C}$. An increase in the lutetia content in the samples to 40 and 70 mol\% leads to an increase in the starting densification temperature $\left(\sim 730-740{ }^{\circ} \mathrm{C}\right)$ and a decrease in the shrinkage rate, which is especially characteristic of the $\left(\mathrm{Lu}_{0.7} \mathrm{~Tb}_{0.3}\right)_{2} \mathrm{O}_{3}$ composition. The position of the first shrinkage peak maximum, corresponding to the reduction of the $\mathrm{Tb}^{4+}$ ions, shifts towards higher temperatures, while the peak intensity decreases. Also a tiny peak arises at $\sim 980{ }^{\circ} \mathrm{C}$, characteristic of the crystallization of pristine lutetia. $\left(\mathrm{Lu}_{0.4} \mathrm{~Tb}_{0.6}\right)_{2} \mathrm{O}_{3}$ and $\left(\mathrm{Lu}_{0.7} \mathrm{~Tb}_{0.3}\right)_{2} \mathrm{O}_{3}$ compacts exhibit a total shrinkage of about $31 \%$ and $26 \%$ at $1520{ }^{\circ} \mathrm{C}$, respectively. The lower shrinkage rate of compacts with high lutetia content $\left(\mathrm{Lu}_{0.7} \mathrm{~Tb}_{0.3}\right)_{2} \mathrm{O}_{3}$ is likely caused by the higher sintering temperatures of pristine lutetia compared to terbia and an accelerating of this effect at its higher concentration in the sample.

A different situation is observed when terbia is doped by $10 \mathrm{~mol} \%$ of yttria. The additive promotes an increase in the shrinkage rate of the compact in the entire studied temperature range. The compact $\left(\mathrm{Y}_{0.1} \mathrm{~Tb}_{0.9}\right)_{2} \mathrm{O}_{3}$ exhibits a total shrinkage of about $35 \%$ at $1520{ }^{\circ} \mathrm{C}$. An intensive change in the shrinkage rate of the sample begins at about $650{ }^{\circ} \mathrm{C}$, which is lower than the temperature for pristine terbia, and ends at about $1000{ }^{\circ} \mathrm{C}$. The introduction of even small amounts of yttria contributes to the intensification of terbia reduction (which agrees with the XRD data) and, as a consequence, to ceramic
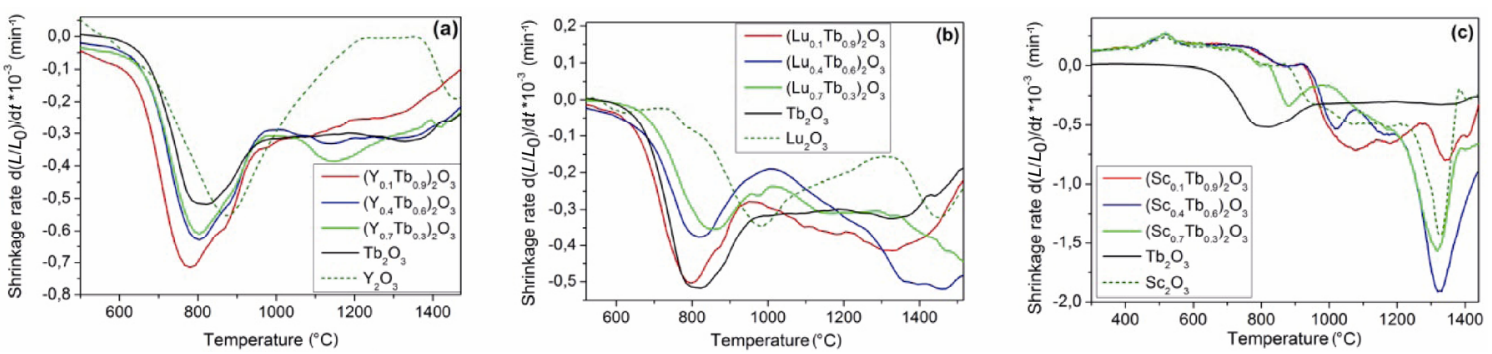

Fig. 3 Shrinkage rate curves of SHS powder compacts of terbia and compounds of terbia with (a) yttria, (b) lutetia, and (c) scandia. 
densification. However, further dilution of the terbia matrix leads to a decrease in the shrinkage rate. For the $\left(\mathrm{Y}_{0.1} \mathrm{~Tb}_{0.9}\right)_{2} \mathrm{O}_{3}$ and $\left(\mathrm{Y}_{0.4} \mathrm{~Tb}_{0.6}\right)_{2} \mathrm{O}_{3}$ compositions, there is a peak that arises at $\sim 870{ }^{\circ} \mathrm{C}$, characteristic for the crystallization of pristine yttria. On the contrary, no such peak is found for the $\left(\mathrm{Y}_{0.7} \mathrm{~Tb}_{0.3}\right)_{2} \mathrm{O}_{3}$ composition. A possible explanation for this may be that partial oxidation of $\mathrm{Tb}^{3+}$ results in distinct structural distortions of C-type solid-solutions with a terbium content of more than $50 \mathrm{~mol} \%$ [13]. During reduction of terbium ions, two-phase system may appear [13] whose behavior is manifested on the dilatometric curves as a superposition of pristine yttria and terbia-yttria solid solution at temperatures below $\sim 1000{ }^{\circ} \mathrm{C}$. If terbium content is less than $50 \mathrm{~mol} \%$ (for $\left(\mathrm{Y}_{0.7} \mathrm{~Tb}_{0.3}\right)_{2} \mathrm{O}_{3}$ composition), the two-phase system does not appear, so a peak at $\sim 870{ }^{\circ} \mathrm{C}$ is not observed. The densification rates of $\left(\mathrm{Y}_{0.4} \mathrm{~Tb}_{0.6}\right)_{2} \mathrm{O}_{3}$ and $\left(\mathrm{Y}_{0.7} \mathrm{~Tb}_{0.3}\right)_{2} \mathrm{O}_{3}$ samples have an intermediate value between pristine terbia and that doped by $10 \mathrm{~mol} \%$ of yttria. The total shrinkage of $\left(\mathrm{Y}_{0.4} \mathrm{~Tb}_{0.6}\right)_{2} \mathrm{O}_{3}$ and $\left(\mathrm{Y}_{0.7} \mathrm{~Tb}_{0.3}\right)_{2} \mathrm{O}_{3}$ samples amounts to about $33 \%$ at $1520{ }^{\circ} \mathrm{C}$.

The introduction of scandia into terbia leads to a significant decrease in the shrinkage rate of the samples in the temperature range up to $950{ }^{\circ} \mathrm{C}$. This is associated with the lower content of tetravalent terbium ions in the samples. The lower content of $\mathrm{Tb}^{4+}$ is also noticeable in terms of the color of the reduced powders of the compounds $\left(\mathrm{Sc}_{1-x} \mathrm{~Tb}_{x}\right)_{2} \mathrm{O}_{3}$, which do not have a brown shade typical of $\left(\mathrm{Y}_{1-x} \mathrm{~Tb}_{x}\right)_{2} \mathrm{O}_{3}$ and $\left(\mathrm{Lu}_{1-x} \mathrm{~Tb}_{x}\right)_{2} \mathrm{O}_{3}$. Probably, scandia contributes to a slowing down of the process of terbium oxidation at the synthesis stage, the intensification of $\mathrm{Tb}^{4+}$ ions reduction, as well as the supression of the crystalization of terbia-scandia compounds. On the dilatometric curves of terbia samples containing 40 and $70 \mathrm{~mol} \%$ of scandia, only small peaks with a maxima at temperatures of about 1020 and $880{ }^{\circ} \mathrm{C}$, respectively, are observed, which is probably responsible for the $\mathrm{Tb}^{4+}$ ion reduction. On the dilatometric curve of a terbia sample with $10 \mathrm{~mol} \%$ of scandia, the shrinkage peaks are combined into one broad double peak. The densification rate of the $\left(\mathrm{Sc}_{0.1} \mathrm{~Tb}_{0.9}\right)_{2} \mathrm{O}_{3}$ sample at a temperature above $950{ }^{\circ} \mathrm{C}$ is higher than that of pristine terbia. At temperatures above $1100{ }^{\circ} \mathrm{C}$, a significant increase in the shrinkage rate is observed in $\left(\mathrm{Sc}_{0.4} \mathrm{~Tb}_{0.6}\right)_{2} \mathrm{O}_{3}$ and $\left(\mathrm{Sc}_{0.7} \mathrm{~Tb}_{0.3}\right)_{2} \mathrm{O}_{3}$ samples, which is shown by a very intense peak on the dilatometric curves. The position of the peaks' maxima almost coincides with the position of the corresponding peak for pristine scandia, but the densification rate (compared to $\mathrm{Sc}_{2} \mathrm{O}_{3}$ ) is much higher. The effect of the increasing densification rate of the terbia-scandia compounds at high temperatures can be explained by activation of the dislocations diffusion due to the formation of terbium scandiate $\mathrm{TbScO}_{3}$ (as will be seen later).

The estimation of the sinterability of SHS powders of compounds of terbia with scandia, yttria, and lutetia microwave sintering was carried out in the temperature range of $1450-1720{ }^{\circ} \mathrm{C}$ for $15-210 \mathrm{~min}$. The prospects of using MW heating for production of optical ceramics are determined by the following main factors. The absence of heating elements in the working chambers ensures sintering in high vacuum conditions. Pollution of grain boundaries with the material of the evaporating heating elements is a significant issue in the process of ceramic sintering in the traditional ovens. Due to the volume character of $\mathrm{MW}$ heating, the temperature distribution has a maximum inside the sintered product, by contrast with the temperature distribution in the case of resistive heating. At this temperature profile, porosity on the product periphery remains open until a later sintering stage, which contributes to ejection of pores and achievement of a higher compaction rate. Figure 4 shows some SEM micrographs of the MW sintered samples. The density of the samples after sintering and the estimated values of the average grain size, are shown in Table 2.

As can be seen from Fig. 4 and Table 2, the introduction of yttria, lutetia, and scandia to terbia leads to an increase, both in the ceramic density and in the average grain size (which is typical for mixed
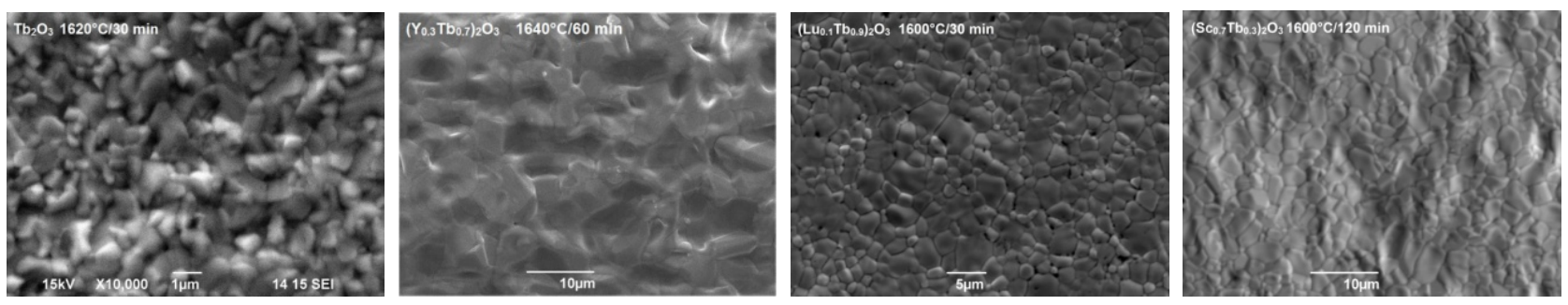

Fig. 4 SEM micrographs of $\mathrm{Tb}_{2} \mathrm{O}_{3},\left(\mathrm{Y}_{1-x} \mathrm{~Tb}_{x}\right)_{2} \mathrm{O}_{3},\left(\mathrm{Lu}_{1-x} \mathrm{~Tb}_{x}\right)_{2} \mathrm{O}_{3}$, and $\left(\mathrm{Sc}_{1-x} \mathrm{~Tb}_{x}\right)_{2} \mathrm{O}_{3}$ microwave sintered ceramics. 
Table 2 Density and average grain size of the samples after microwave sintering

\begin{tabular}{cccc}
\hline Sample & Sintering temperature $\left({ }^{\circ} \mathrm{C}\right)$ & Soaking time $(\mathrm{min})$ & Density $\rho\left(\mathrm{g} / \mathrm{cm}^{3}\right)$ and $\rho / \rho_{\text {theory }}$ \\
\hline $\mathrm{Tb}_{2} \mathrm{O}_{3}$ & 1450 & 15 & $6.475,0.82$ \\
$\mathrm{~Tb}_{2} \mathrm{O}_{3}$ & 1620 & 30 & $7.372,0.93$ \\
$\left(\mathrm{Y}_{0.3} \mathrm{~Tb}_{0.7}\right)_{2} \mathrm{O}_{3}$ & 1640 & 60 & $6.61,0.95$ \\
$\left(\mathrm{Y}_{0.9} \mathrm{~Tb}_{0.1}\right)_{2} \mathrm{O}_{3}$ & 1640 & 60 & $5.29,0.99$ \\
$\left(\mathrm{Lu}_{0.7} \mathrm{~Tb}_{0.3}\right)_{2} \mathrm{O}_{3}$ & 1500 & 60 & $6.67,0.75$ \\
$\left(\mathrm{Lu}_{0.7} \mathrm{~Tb}_{0.3}\right)_{2} \mathrm{O}_{3}$ & 1650 & 60 & 7 \\
$\left(\mathrm{Lu}_{0.4} \mathrm{~Tb}_{0.6}\right)_{2} \mathrm{O}_{3}$ & 1600 & 30 & $8.7,0.972$ \\
$\left(\mathrm{Lu}_{0.4} \mathrm{~Tb}_{0.6}\right)_{2} \mathrm{O}_{3}$ & 1600 & 210 & $8.394,0.989$ \\
$\left(\mathrm{Lu}_{0.4} \mathrm{~Tb}_{0.6}\right)_{2} \mathrm{O}_{3}$ & 1650 & 60 & $8.395,0.99$ \\
$\left(\mathrm{Lu}_{0.1} \mathrm{~Tb}_{0.9}\right)_{2} \mathrm{O}_{3}$ & 1600 & 30 & $8.37,0.986$ \\
$\left(\mathrm{Lu}_{0.1} \mathrm{~Tb}_{0.9}\right)_{2} \mathrm{O}_{3}$ & 1600 & 210 & 7.5 \\
$\left(\mathrm{Lu}_{0.1} \mathrm{~Tb}_{0.9}\right)_{2} \mathrm{O}_{3}$ & 1640 & 30 & $4.957(0.99)$ \\
$\left(\mathrm{Sc}_{0.7} \mathrm{~Tb}_{0.3}\right)_{2} \mathrm{O}_{3}$ & 1600 & 120 & $7.96(0.99)$ \\
$\left(\mathrm{Sc}_{0.4} \mathrm{~Tb}_{0.6}\right)_{2} \mathrm{O}_{3}$ & 1600 & 100 & 3 \\
$\left(\mathrm{Sc}_{0.1} \mathrm{~Tb}_{0.9}\right)_{2} \mathrm{O}_{3}$ & 1600 & 100 & $7.807(0.971)$ \\
\hline
\end{tabular}

oxides of other rare earth metals) at identical sintering temperatures. The obtained data are in good agreement with the results of dilatometric analysis, which indicates an increase in the densification of mixed oxides compared with pristine terbia. Thus, the sintering of terbia samples with 10 and $40 \mathrm{~mol} \%$ of lutetia at a temperature of $1600{ }^{\circ} \mathrm{C}$ for 30 min leads to the producing of ceramics with density equal to $99 \%$ of theoretical value. $\left(\mathrm{Lu}_{0.4} \mathrm{~Tb}_{0.6}\right)_{2} \mathrm{O}_{3}$ and $\left(\mathrm{Lu}_{0.1} \mathrm{~Tb}_{0.9}\right)_{2} \mathrm{O}_{3}$ samples are characterized by grain size distribution with maxima at about 1.5 and $3 \mu \mathrm{m}$ respectively. A further increase in temperature or sintering time leads to an increase in the average grain size. The ceramic samples of terbia with $70 \mathrm{~mol} \%$ of lutetia at the same sintering temperatures have quite a few pores at the grain boundaries, which form cavities comparable in size or larger than grains. This might be caused by the higher sintering temperatures of lutetia (compared with terbia) and the enhancement of this effect with an increase in its content in the sample. Consequently, each composition requires the selection of its own sintering conditions. The addition of more than $10 \mathrm{~mol} \%$ of scandia to terbia contributes to the intensification of the sintering of the samples in comparison with pristine $\mathrm{Tb}_{2} \mathrm{O}_{3}$. However, the densification rate and the density values at identical sintering temperatures are somewhat lower than those for solid solutions with yttria and lutetia. This can be explained by the presence of the mixure of oxides $\mathrm{Sc}_{2} \mathrm{O}_{3}, \mathrm{TbScO}_{3}, \mathrm{~Tb}_{2} \mathrm{O}_{3}$ in the $\left(\mathrm{Sc}_{1-x} \mathrm{~Tb}_{x}\right)_{2} \mathrm{O}_{3}$ sintered ceramics (see Fig. 5). Also, a diffuse halo corresponding to the amorphous state is observed in the region of the most intense peak in the XRD patterns of $\left(\mathrm{Sc}_{1-x} \mathrm{~Tb}_{x}\right)_{2} \mathrm{O}_{3}$ sintered ceramics.

Nevertheless, despite the high density, all the samples

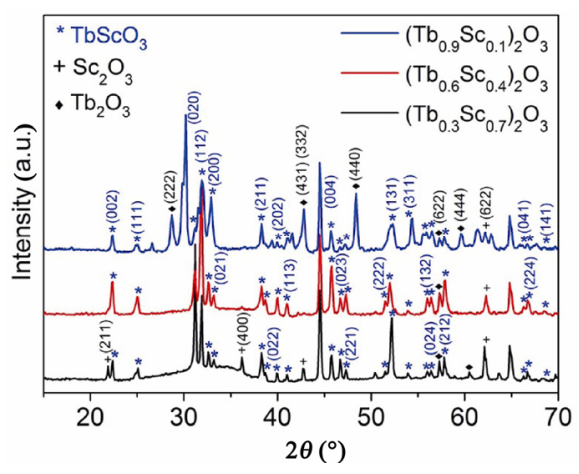

Fig. 5 XRD patterns of $\left(\mathrm{Sc}_{1-x} \mathrm{~Tb}_{x}\right)_{2} \mathrm{O}_{3}$ ceramics.

are only translucent; the light transmission at a wavelength of $1 \mu \mathrm{m}$ does not exceed $30 \%$ (see Fig. 6). The low transmission of terbia-yttria and terbia-lutetia solid solution ceramics is connected with the presence of inter- and intragranular pores, which are the main cause of light scattering. Their formation can be associated with both the non-optimal sintering mode of the samples, and the oxygen release that occurs during the reduction of the $\mathrm{Tb}^{4+}$ ions at temperatures of $700-1000{ }^{\circ} \mathrm{C}$. The pressure of the oxygen trapped within a closed pore counteracts the surface tension driving force to shrink the pore during sintering. Further improvement in the optical quality of ceramics can be achieved by optimizing the sintering conditions.

In the case of compounds of terbia with scandia, the pore concentration is noticeably lower and insufficient for such intense scattering. In this connection, we assume that the main scattering mechanism in these samples is second phase scattering. This assumption can be confirmed by a significant $(2 \%-3 \%)$ deviation in the ceramic density from the theoretical value against a background of insignificant porosity. 


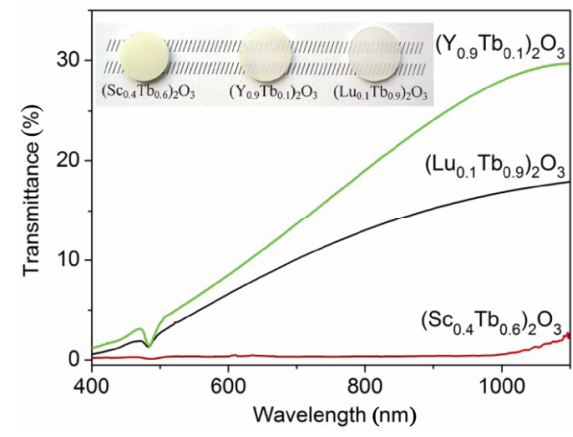

Fig. 6 Transmission spectrum and appearance of $\left(\mathrm{Sc}_{0.4} \mathrm{~Tb}_{0.6}\right)_{2} \mathrm{O}_{3},\left(\mathrm{Y}_{0.9} \mathrm{~Tb}_{0.1}\right)_{2} \mathrm{O}_{3}$, and $\left(\mathrm{Lu}_{0.1} \mathrm{~Tb}_{0.9}\right)_{2} \mathrm{O}_{3}$ ceramics.

\section{Conclusions}

Nanopowders of terbia compounds with scandia, yttria, and lutetia were successfully produced by the SHS method using a mixture of nitrates of metals and glycine as a precursor. The XRD patterns have indicated that the $\left(\mathrm{Y}_{1-x} \mathrm{~Tb}_{x}\right)_{2} \mathrm{O}_{3}$ and $\left(\mathrm{Lu}_{1-x} \mathrm{~Tb}_{x}\right)_{2} \mathrm{O}_{3}$ samples $(x=$ $0.3,0.6,0.9)$ represent solid solutions of yttria or lutetia and terbia. A mechanical mixture of oxides $\mathrm{Sc}_{2} \mathrm{O}_{3}, \mathrm{TbScO}_{3}, \mathrm{~Tb}_{2} \mathrm{O}_{3}$ and amorphous phase is typical for the $\left(\mathrm{Sc}_{1-x} \mathrm{~Tb}_{x}\right)_{2} \mathrm{O}_{3}$ sample. Lutetium ions have a negligible effect on the phase formation in terbia; on the contrary, yttrium ions and, especially, scandium ions significantly suppress crystallization and formation of the $\mathrm{Tb}_{2} \mathrm{O}_{3}$ cubic phase.

The introduction of small amounts of yttria or lutetia contributes to the intensification of the terbia ceramics' densification and producing of samples with density equal to $99 \%$ of theoretical value when heated in a microwave field. The lower densification rate and the density of ceramics of compounds of scandia-terbia are due to the presence of the second phases. The study conducted on the temperature and composition dependences of the phase transformations and on the microstructure in polycrystalline terbia with the addition of yttria, lutetia, and scandia formed the basis for the development of new technology of high optical quality terbia-based ceramics for magneto-optical laser devices.

\section{Acknowledgements}

This work was supported by the Russian Foundation for Basic Research (Grant No. 16-03-00595).

\section{References}

[1] Snetkov IL, Voitovich AV, Palashov OV, et al. Review of Faraday isolators for kilowatt average power lasers. IEEE $J$ Quantum Elect 2014, 50: 434-443.

[2] Khazanov EA. Investigation of Faraday isolator and Faraday mirror designs for multi-kilowatt power lasers. In: Proceedings Volume 4968, Solid State Lasers XII. Scheps R, Ed. 2003: 115.

[3] Chen $\mathrm{C}$, Yi X, Zhang S, et al. Vacuum sintering of $\mathrm{Tb}_{3} \mathrm{Al}_{5} \mathrm{O}_{12}$ transparent ceramics with combined TEOS $+\mathrm{MgO}$ sintering aids. Ceram Int 2015, 41: 12823-12827.

[4] Starobor A, Zheleznov D, Palashov O, et al. Study of the properties and prospects of Ce:TAG and TGG magnetooptical ceramics for optical isolators for lasers with high average power. Opt Mater Express 2014, 4: 2127-2132.

[5] Snetkov IL, Yasuhara R, Starobor AV, et al. Thermo-optical and magneto-optical characteristics of terbium scandium aluminum garnet crystals. IEEE J Quantum Elect 2015, 51: $1-7$.

[6] Starobor A, Yasyhara R, Snetkov I, et al. TSAG-based cryogenic Faraday isolator. Opt Mater 2015, 47: 112-117.

[7] Snetkov IL, Permin DA., Balabanov SS, et al. Wavelength dependence of Verdet constant of $\mathrm{Tb}^{3+}: \mathrm{Y}_{2} \mathrm{O}_{3}$ ceramics. Appl Phys Lett 2016, 108: 161905.

[8] Adachi G, Imanaka N. The binary rare earth oxides. Chem Rev 1998, 98: 1479-1514.

[9] Balabanov SS, Permin DA, Rostokina EY, et al. Synthesis and structural characterization of ultrafine terbium oxide powders. Ceram Int 2017, 43: 16569-16574.

[10] Zinkevich M. Thermodynamics of rare earth sesquioxides. Prog Mater Sci 2007, 52: 597-647.

[11] Coutures J, Rouanet A, Verges R, et al. Etude a haute température des systèmes formes par le sesquioxyde de lanthane et les sesquioxydes de lanthanides. I. Diagrammes de phases $\left(1400^{\circ} \mathrm{C}<T<T\right.$ Liquide). $J$ Solid State Chem 1976, 17: 171-182.

[12] Shimada T. Magneto-optical ceramic material and method for selecting same. US Patent 9052415 B2. 2012.

[13] Glushkova VB. Phase ratios in $\mathrm{YO}_{1.5}-\mathrm{TbO}_{1.5}$ and $\mathrm{YO}_{1.5}$ $\mathrm{TbO}_{x}$ systems. Inorg Mater (USSR) (Engl Transl) 1988, 24: 665-669.

[14] Petrova MA, Grebenshchikov RG. Specific features of the phase formation in the titanate systems $\mathrm{Ln}_{2} \mathrm{TiO}_{5}-\mathrm{Ln}_{2}{ }_{2} \mathrm{TiO}_{5}$ ( $\left.L n=\mathrm{La}, \mathrm{Gd}, \mathrm{Tb}, \mathrm{Er} ; L n^{\prime}=\mathrm{Tb}, \mathrm{Lu}\right)$. Glass Phys Chem 2008, 34: 603-607.

[15] Zhang J, Von Dreele RB, Eyring L. The structures of $\mathrm{Tb}_{7} \mathrm{O}_{12}$ and $\mathrm{Tb}_{11} \mathrm{O}_{20}$. J Solid State Chem 1993, 104: 21-32.

[16] Yavetskiy RP, Baumer VN, Danylenko MI, et al. Transformation-assisted consolidation of $\mathrm{Y}_{2} \mathrm{O}_{3}: \mathrm{Eu}^{3+}$ nanospheres as a concept to optical nanograined ceramics. Ceram Int 2014, 40: 3561-3569.

Open Access The articles published in this journal are distributed under the terms of the Creative Commons Attribution 4.0 International License (http://creativecommons.org/licenses/by/4.0/), which permits unrestricted use, distribution, and reproduction in any medium, provided you give appropriate credit to the original author(s) and the source, provide a link to the Creative Commons license, and indicate if changes were made. 